\title{
FORMULATION AND EVALUATION OF NOVEL CHROMENE DERIVATIVE AS AN ANTI-INFLAMMATORY AGENT USED FOR INFLAMMATORY BOWEL DISEASES
}

\author{
RESHMI KP ${ }^{1}$, SUBIN MARY ZACHARIAH ${ }^{2}$, VIDYA VISWANAD ${ }^{1 *}$
}

\begin{abstract}
${ }^{1}$ Department of Pharmaceutics, Amrita School of Pharmacy, Amrita Vishwa Vidyapeetham, Amrita University, AIMS Health Sciences Campus, Kochi, Kerala, India. ${ }^{2}$ Department of Pharmaceutical Chemistry, Amrita School of Pharmacy, Amrita Vishwa Vidyapeetham, Amrita University, AIMS Health Sciences Campus, Kochi, Kerala, India. Email: vidyaviswanad@aims.amrita.edu
\end{abstract}

Received: 15 October 2016, Revised and Accepted: 29 October 2016

ABSTRACT

Objective: To formulate and evaluate an extended-release (ER) tablet of a new molecule, 2-amino-4-(4-bromophenyl)-7-hydroxy-4H-chromene-3carbonitrile using a combination of two polymers (hydroxypropyl methyl cellulose [HPMC] K100 and HPMC phthalate) which control the rate and degree of the drug release through $12 \mathrm{hrs}$ period and protect the drug release from acidic $\mathrm{pH}$.

Methods: Five batches of tablets (4HC1, 4HC2, 4HC3, 4HC4, 4HC5) were produced by direct compression method. Morphological evaluation of the powder blend was carried out by differential scanning calorimetry and Powered X-ray diffractometry. The evaluation studies such as flow properties, hardness, friability, drug content, and release study were conducted according to pharmacopoeial standards.

Results: The physicochemical characteristics of all the granules and tablets were generally satisfactory. The drug release followed zero order, Higuchi model kinetics with diffusion and dissolution mediated mechanism. Tablets were evaluated for physicochemical parameters and promising. Stability studies indicated the dosage form is stable for 3 months at accelerated conditions.

Conclusion: From the results received from all test, it was concluded that formulation 4 HC 4 are the most suitable choice for developing 12 hrs ER tablets. This finding reveals that a particular concentration of HPMC K100 was capable of producing ER.

Keywords: Chromene derivative, Extended-release, Hydroxypropyl methylcellulose phthalate, Hydroxypropyl methylcellulose K100.

(C) 2017 The Authors. Published by Innovare Academic Sciences Pvt Ltd. This is an open access article under the CC BY license (http://creativecommons. org/licenses/by/4. 0/) DOI: http://dx.doi.org/10.22159/ajpcr.2017.v10i2.15696

\section{INTRODUCTION}

Inflammatory bowel disease (IBD) is a chronic gastrointestinal (GI) disorder which includes ulcerative colitis and Crohns disease. The exact cause of disease is undefined; certain factors have been suggested to play a role, such as genetics, microbiome, environmental stress, and immune dysfunction. Current therapeutic agents are limited for use in IBDs as they are generally designed to achieve systemic delivery of therapeutics, which results in adverse effects and toxicity following distribution of drug around the body. Oral formulations achieving a localized effect are preferred in rational drug delivery design for IBD. Current therapeutic approaches specifically indicated for IBD rely on conventional dosage forms such as delayed or extended release (ER) mechanisms [1,2]. Conventional drug delivery systems are failed to treat such diseases because the drugs do not offer site-specific drug delivery. Hence, the site specific delivery of drugs is promising tool for such diseases whereby minimizing the side effects that occur because of unnecessary systemic absorption [3].

There are several methods available for site-specific drug delivery $[4,5]$ :

- The use of carriers that degrade exclusively by intestinal bacteria

- Using pH dependent polymers

- $\quad$ Time-dependent dosage forms

- Prodrugs

ER dosage forms are designed to achieve a prolonged therapeutic effect by continuously releasing the drug over an extended period after administration of a single dose [6,7]. The advantages of ER dosage forms over conventional forms include the less fluctuation in drug blood levels, frequency reduction in dosing, enhanced convenience, and compliance, reduction in adverse effects and reduction in overall health-care costs.
2-amino-4H-chromene derivatives with nitrile functionality have wide application in tumor necrosis factor $\alpha$ (TNF- $\alpha$ ) mediated disease such as IBD, rheumatoid arthritis, and other inflammation mediated disease [8-10]. Chromene moiety represents a novel class of TNF- $\alpha$ inhibitor, one of the best examples in this class is 2-amino4-(4-bromophenyl)-7-hydroxy-4H-chromene-3-carbonitrile is a novel chromene derivative (Fig. 1) [11]. The compound is synthesized by condensation reaction of malononitrile, substituted aldehyde, and activated phenol in the presence of an organic base (pyridine) for several $[12,13]$. The solubility of the synthesized compound enhanced by complexation technique using hydroxypropyl beta cyclodextrin.

The main objective of the present study to formulate site-specific drug delivery system containing a chromene derivative using polymers like hydroxypropyl methylcellulose (HPMC) phthalate and HPMC K100 and evaluates its physical parameters and in vitro drug release studies. The aim of present study was to formulate and evaluate an ER tablet of a new molecule 2-amino-4-(4-bromophenyl)-7-hydroxy-4H-chromene3-carbonitrile using a combination of two polymers (HPMC K100 and HPMC phthalate). Which control the rate and degree of the drug release through $12 \mathrm{hrs}$ period and protect the drug release from acidic $\mathrm{pH}$. Sitespecific drug delivery devices are provided with a pH-sensitive polymer. Many studies have indicated the considerable variation in $\mathrm{pH}$ gradient in the GI tract; therefore, completely depending on the $\mathrm{pH}$ sensitivity of the polymer. In this research work, the ER tablets were compressed with varying proportions of HPMC phthalate and HPMC K100 and studied in vitro for their release profile in various $\mathrm{pH}$ conditions. The drug release kinetics was studied by using various kinetic studies available, such as Higuchi, Korsemeyer-Peppas, zero order, and first order kinetics. The results of the overall study, release kinetics, and mechanism of drug release were elaborately discussed in this work. 


\section{METHODS}

2-amino-4-(4-bromophenyl)-7-hydroxy-4H-chromene-3-carbonitrile is synthesized in our laboratory. HPMC K100, microcrystalline cellulose 102 (MCC 102), lactose, aerosil, and magnesium stearate were purchased from Yarrow chem products Mumbai. HPMC phthalate was purchased from Colorcon Asia Pvt. Ltd. Goa.

\section{Calibration graph of synthesized drug}

Weigh $10 \mathrm{mg}$ of synthesized compound; add sufficient quantity of methanol to produce a stock solution of $100 \mu \mathrm{g} / \mathrm{ml}$. From the standard stock solution, dilutions were made into the concentration of $10-50 \mu \mathrm{g} / \mathrm{ml}$. Take the absorbance at $318 \mathrm{~nm}$ on ultraviolet spectrophotometer against blank.

\section{Preparation of ER tablet}

Direct compression method was used to prepare ER tablets of newly synthesized compound. Required amount of the, synthesized drug, MCC 102 , lactose, polymers were taken and were sieved through \#44. It was then mixed with magnesium stearate and aerosil which was previously sieved using \#60. Five different set of tablets were prepared on rotary compression machine $[14,15]$.

\section{Evaluation studies}

The granules were evaluated for various physicochemical parameters including angle of repose, bulk density, tap density, compressibility index and Hausner ratio. The prepared powder blend was characterized by differential scanning calorimetry (DSC) and Powered X-ray diffractometery (PXRD).

The compressed tablets were characterized by their physicochemical parameters. The hardness of the tablets was tested using Monsanto tablet hardness tester. The average weight was also determined as per (Indian Pharmacopoeia [IP]). 10 tablets from each batch of formulations were selected randomly, and thickness of tablets was measured using vernier caliper. The Friability was determined in roche friabilator. Friability was calculated as a percentage of weight loss after 100 rotations (IP).

\section{Drug release study}

In vitro dissolution studies were performed using the United States Pharmacopeia (USP) dissolution apparatus II. The volume of dissolution

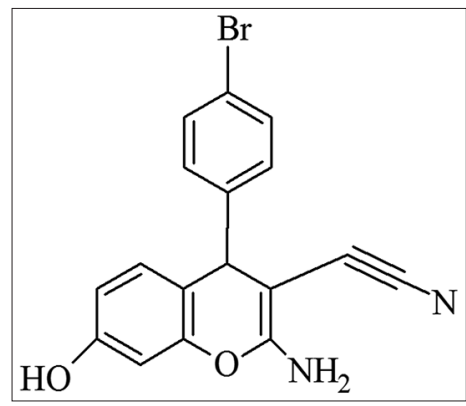

Fig. 1: 2-amino-4-(4-bromophenyl)-7-hydroxy-4H-chromene-3carbonitrile

Table 1: Formula for 1 tablet with formulation code

\begin{tabular}{|c|c|c|c|c|c|}
\hline Ingredients (mg) & 4HC1 & $4 \mathrm{HC2}$ & $4 \mathrm{HC} 3$ & $4 \mathrm{HC} 4$ & $4 \mathrm{HC5}$ \\
\hline Drug & 30 & 30 & 30 & 30 & 30 \\
\hline HPMC K100 & 15 & 30 & 45 & 53.136 & 60 \\
\hline MCC 102 & 64.05 & 25.92 & 25.92 & 25.92 & 31.784 \\
\hline Lactose & 54.75 & 77.5 & 69.75 & 54.75 & 54.75 \\
\hline $\begin{array}{l}\text { Hypromellose } \\
\text { phthalate }\end{array}$ & 52 & 52 & 52 & 52 & 52 \\
\hline Magnesium stearate & 0.81 & 0.81 & 0.81 & 0.81 & 0.81 \\
\hline Aerosil & 0.81 & 0.81 & 0.81 & 0.81 & 0.81 \\
\hline
\end{tabular}

Drug: Synthesized drug-HP $\beta C D$ complex, HPMC K100: Hydroxypropyl

methylcellulose, MCC 102: Microcrystalline cellulose 102 medium was $900 \mathrm{ml}$, and it was maintained at $37 \pm 0.5^{\circ} \mathrm{C}$ and stirred at paddle speed of $50 \mathrm{rpm}$. Simulated gastric fluid (pH 1.2) and simulated intestinal fluid (pH 7.4), prepared according to standard monograph without enzymes were used as dissolution media. Dissolution test was run for $1 \mathrm{hr}$ in simulated gastric fluid and subsequently on stimulated intestinal fluid. $5 \mathrm{ml}$ of samples were collected at time intervals of $5,10,15,20,30,45,60$ minutes and replaced by the equal amount of dissolution medium to maintain a constant volume. Samples were analyzed spectrophotometrically at $318 \mathrm{~nm}$ to determine the amount of drug released from which the percentage drug release was calculated.

\section{Stability study}

The stability studies were performed both at room temperature and accelerated stability study conditions. The prepared formulations were stored at $40 \pm 2^{\circ} \mathrm{C}$ and $75 \pm 5^{\circ} \mathrm{C}$ relative humidity in a stability chamber for 3 months and observed the physical changes occurred in each month.

\section{RESULTS}

\section{Calibration curve}

Fig. 2 indicates the standard calibration curve of synthesized compound. The absorbance of the different concentration of synthesized drug was measured using methanol as a blank $\left(\lambda_{\max }=318 \mathrm{~nm}\right)$, and the correlation coefficient $\left(R^{2}\right)$ was found to be 0.994 .

\section{Evaluation of granules}

All the data obtained were compared with the standard value mentioned in IP. Based on the criteria, it was found that the all the ER tablets have well flow properties and better compressibility. Table 2 represents the Physical characteristics of the prepared granules.

The bulk density of the granules ranged from 0.57 to $0.62 \mathrm{~g} / \mathrm{ml}$ and tapped density from 0.58 to $0.67 \mathrm{~g} / \mathrm{ml}$. The angle of repose of the granules was in the range of $27.94-32.15^{\circ}$.

The compressibility (Carr's index) for all the formulations was $\leq 10 \%$ while Hausner ratio was in the range 1.00-1.11.

\section{Physicochemical characteristics of prepared formulations}

Table 3 indicates the results of the various physicochemical tests (hardness, friability, and drug content) performed on the tablet formulations.

The hardness of the prepared tablets was in the range $5.1-5.8 \mathrm{~kg} / \mathrm{cm}^{2}$. All the formulations showed $<1 \%$ friability which is within the prescribed limit. Drug content was uniform within each batch and ranged from $97.22 \%$ to $98.54 \%$ of the theoretical value.

\section{Characterization of ER tablet by DSC and PXRD}

The thermal behavior of optimized formula and powder blend was studied using DSC. The thermogram of the powder blend shows a characteristic peak of excipients in Figs. 3 and 4.

\section{PXRD}

The PXRD pattern of optimized formulation displayed intense and sharp peaks at $12.40,19.585^{\circ}$ with high intensity. The PXRD were shown in Figs. 5 and 6. The lack of crystallinity in the formulation might be due to solubilization of synthesized molecule in inclusion complex which is absorbed into carrier. This suggested although some crystalline signals of physical mixture were still detectable in the optimized formulation.

\section{In vitro drug release study}

The in vitro drug release results for the 5 different formulations are shown in Fig. 7. From the dissolution study, it was observed that a formulation 4HC4 has the highest release compared to other batches in terms of both the rate and extent of the drug released.

It was concluded that HPMC K100 can be used as an effective extend release polymer to retard the release of drug. The best ER of tablet was obtained from the blend of drug and HPMC K100 in 1:1.8 ratios. 
Table 2: Physical characteristics of powder mixtures

\begin{tabular}{|c|c|c|c|c|c|}
\hline Formulations & $\begin{array}{l}\text { Angle of } \\
\text { repose }\left(^{\circ}\right)\end{array}$ & Bulk density $(\mathrm{g} / \mathrm{ml})$ & Tapped density (g/ml) & Carr's index (\%) & Hausner's ratio \\
\hline $4 \mathrm{HC} 1$ & $32.15 \pm 1.04$ & $0.574 \pm 0.013$ & $0.656 \pm 0.018$ & $9.54 \pm 0.58$ & $1.023 \pm 0.010$ \\
\hline $4 \mathrm{HC} 2$ & $29.16 \pm 1.06$ & $0.577 \pm 0.010$ & $0.612 \pm 0.017$ & $9.07 \pm 0.54$ & $1.034 \pm 0.012$ \\
\hline $4 \mathrm{HC} 3$ & $28.23 \pm 1.07$ & $0.573 \pm 0.014$ & $0.589 \pm 0.019$ & $9.84 \pm 0.63$ & $1.048 \pm 0.015$ \\
\hline $4 \mathrm{HC} 4$ & $27.45 \pm 1.08$ & $0.611 \pm 0.015$ & $0.627 \pm 0.013$ & $10.44 \pm 0.52$ & $1.037 \pm 0.011$ \\
\hline $4 \mathrm{HC} 5$ & $27.94 \pm 1.04$ & $0.628 \pm 0.013$ & $0.677 \pm 0.017$ & $9.04 \pm 0.67$ & $1.032 \pm 0.015$ \\
\hline
\end{tabular}

Table 3: Physicochemical characteristics of prepared ER tablets

\begin{tabular}{|c|c|c|c|c|c|}
\hline $\begin{array}{l}\text { Formulation } \\
\text { code }\end{array}$ & $\begin{array}{l}\text { Hardness } \\
\left(\mathrm{kg} / \mathrm{cm}^{2}\right)\end{array}$ & $\begin{array}{l}\text { Thickness } \\
\text { (mm) }\end{array}$ & $\begin{array}{l}\text { Friability } \\
\text { (\% loss) }\end{array}$ & $\begin{array}{l}\text { Weight variation } \\
\text { (mg) }\end{array}$ & $\begin{array}{l}\text { Drug content } \\
(\%)\end{array}$ \\
\hline $4 \mathrm{HC} 1$ & $5.5 \pm 0.04$ & $4.15 \pm 0.11$ & $0.49 \pm 0.068$ & $168.42 \pm 0.035$ & $97.22 \pm 0.24$ \\
\hline $4 \mathrm{HC} 2$ & $5.8 \pm 0.35$ & $4.27 \pm 0.10$ & $0.45 \pm 0.0 .016$ & $167.54 \pm 0.741$ & $98.54 \pm 0.32$ \\
\hline $4 \mathrm{HC} 3$ & $5.1 \pm 0.21$ & $4.26 \pm 0.13$ & $0.38 \pm 0.073$ & $167.66 \pm 0.137$ & $98.42 \pm 0.35$ \\
\hline $4 \mathrm{HC} 4$ & $5.7 \pm 0.37$ & $4.23 \pm 0.13$ & $0.55 \pm 0.01$ & $167 \pm 0.212$ & $97.68 \pm 0.47$ \\
\hline $4 \mathrm{HC} 5$ & $5.5 \pm 0.39$ & $4.52 \pm 0.17$ & $0.44 \pm 0.16$ & $166 \pm 0.389$ & $97.51 \pm 0.28$ \\
\hline
\end{tabular}

ER: Extended release

Table 4: In vitro drug release profile of prepared ER tablets

\begin{tabular}{|c|c|c|c|c|c|}
\hline \multirow[t]{2}{*}{ Time (hrs) } & \multicolumn{5}{|c|}{ Cumulative amount of percentage drug release } \\
\hline & 4HC1 & $4 \mathrm{HC} 2$ & 4HC3 & $4 \mathrm{HC} 4$ & 4HC5 \\
\hline 0 (minute) & 0 & 0 & 0 & 0 & 0 \\
\hline 5 (minutes) & $2.02 \pm 0.416$ & $1.97 \pm 0.720$ & $1.55 \pm 0.08$ & $3.80 \pm 0.006$ & $4.001 \pm 0.271$ \\
\hline 10 (minutes) & $6.74 \pm 0.423$ & $4.18 \pm 0.201$ & $3.99 \pm 0.672$ & $9.23 \pm 0.334$ & $8.63 \pm 0.298$ \\
\hline 15 (minutes) & $9.65 \pm 0.296$ & $6.11 \pm 0.03$ & $9.17 \pm 0.543$ & $18.34 \pm 0.543$ & $16.72 \pm 0.373$ \\
\hline 30 (minutes) & $15.25 \pm 0.33$ & $8.911 \pm 0.85$ & $15.63 \pm 0.55$ & $21.10 \pm 0.339$ & $20.11 \pm 0.127$ \\
\hline 45 (minutes) & $18.43 \pm 0.21$ & $14.23 \pm 0.8$ & $18.076 \pm 0.1$ & $23.65 \pm 0.432$ & $23.66 \pm 1.763$ \\
\hline 1 (hr) & $22.06 \pm 0.42$ & $19.93 \pm 0.07$ & $20.31 \pm 0.06$ & $28.36 \pm 0.003$ & $26.78 \pm 0.765$ \\
\hline 2 (hrs) & $27.26 \pm 0.21$ & $26.35 \pm 0.04$ & $28.73 \pm 0.03$ & $39.98 \pm 0.110$ & $28.99 \pm 0.109$ \\
\hline 3 (hrs) & $31.54 \pm 0.223$ & $31.43 \pm 0.333$ & $36.76 \pm 0.438$ & $49.47 \pm 0.22$ & $33.42 \pm 0.080$ \\
\hline 4 (hrs) & $44.32 \pm 0.224$ & $36.78 \pm 0.304$ & $45.33 \pm 0.866$ & $61.754 \pm 0.010$ & $39.57 \pm 0.117$ \\
\hline 6 (hrs) & $49.52 \pm 0.267$ & $39.32 \pm 0.317$ & $53.59 \pm 0.543$ & $72.47 \pm 0.007$ & $47.04 \pm 0.103$ \\
\hline 7 (hrs) & $53.77 \pm 0.287$ & $51.58 \pm 0.264$ & $59.34 \pm 0.414$ & $78.32 \pm 0.372$ & $56.45 \pm 0.677$ \\
\hline 8 (hrs) & $57.53 \pm 0.246$ & $59.41 \pm 0.266$ & $65.44 \pm 0.810$ & $83.66 \pm 0.507$ & $63.33 \pm 0.257$ \\
\hline 9 (hrs) & $64.78 \pm 0.292$ & $65.98 \pm 0.711$ & $76.83 \pm 0.197$ & $85.002 \pm 0.611$ & $69.05 \pm 1.120$ \\
\hline 10 (hrs) & $70.81 \pm 0.518$ & $71.77 \pm 0.681$ & $81.55 \pm 0.185$ & $88.43 \pm 0.2469$ & $78.11 \pm 0.9841$ \\
\hline 12 (hrs) & $83.28 \pm 0.237$ & $81.72 \pm 0.623$ & $80.39 \pm 0.864$ & $90.88 \pm 0.267$ & $76.02 \pm 0.4586$ \\
\hline
\end{tabular}

ER: Extended release

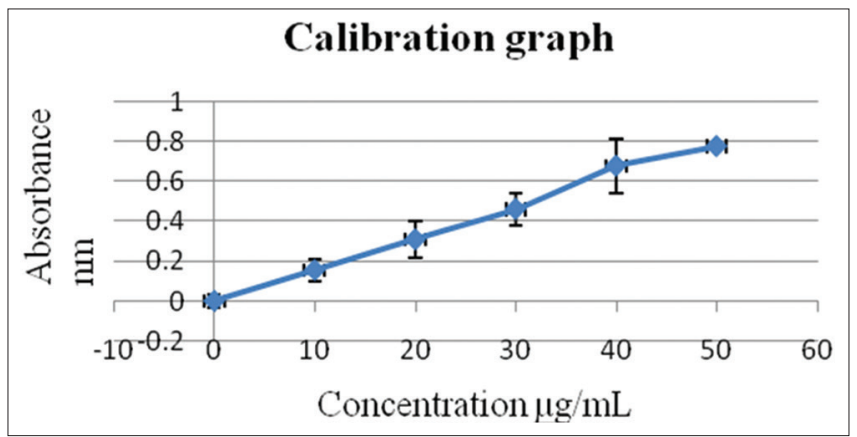

Fig. 2: Calibration graph of synthesized drug

Mathematical modeling of kinetics

The optimized formulation 4HC4 followed zero order kinetic mechanism. In addition, Higuchi as best fitted model, non-Fickian diffusion as the corresponding values of $n$ is lower than or equal to the standard value of Fickian release behavior. Thus, the results point out the mechanistic diffusion and dissolution phenomena. Table 5 mentions kinetic modeling from the optimized formulation.

\section{Stability study}

The physical parameters of tablet kept for stability study were evaluated and compared with the initial values of any significant changes. Results which are shown in Table 5. Stability studies were done for 3 months, and it was noted that surface of tablet free from microbial or fungal growth or bad order. The tablets showed not $<98.5 \%$ drug content and all the physical parameters within the specified limit there was no significance in the values.

\section{DISCUSSION}

In the presented study, ER tablets of synthesized compound were prepared for optimized drug release patterns during in vitro dissolution studies. Various formulations were prepared containing varying amount of polymer to see the effect of polymer concentration on drug release rates. The prepared mixed powder was physically evaluated with some parameters. The average compressibility index of the mixed powder of all the formulations was $\leq 10.44 \pm 0.52$, and average angle of repose was in the range of $27.94-32.15^{\circ}$ which indicates that the mixed powder was having good flow properties. The prepared ER tablets were evaluated for some physical tests. The average hardness of ER tablets was in the range $5.1-5.8 \mathrm{~kg} / \mathrm{cm}^{2}$, average friability was $<1 \%$ and average thickness were in the range 


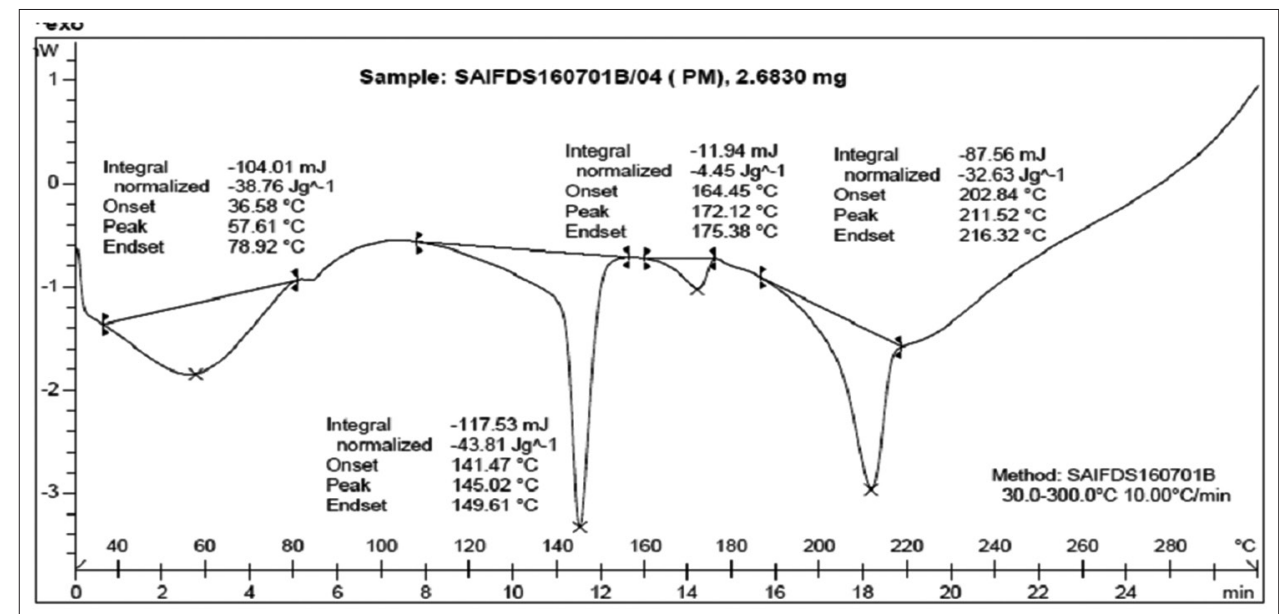

Fig. 3: Differential scanning calorimetry thermogram of physical mixture

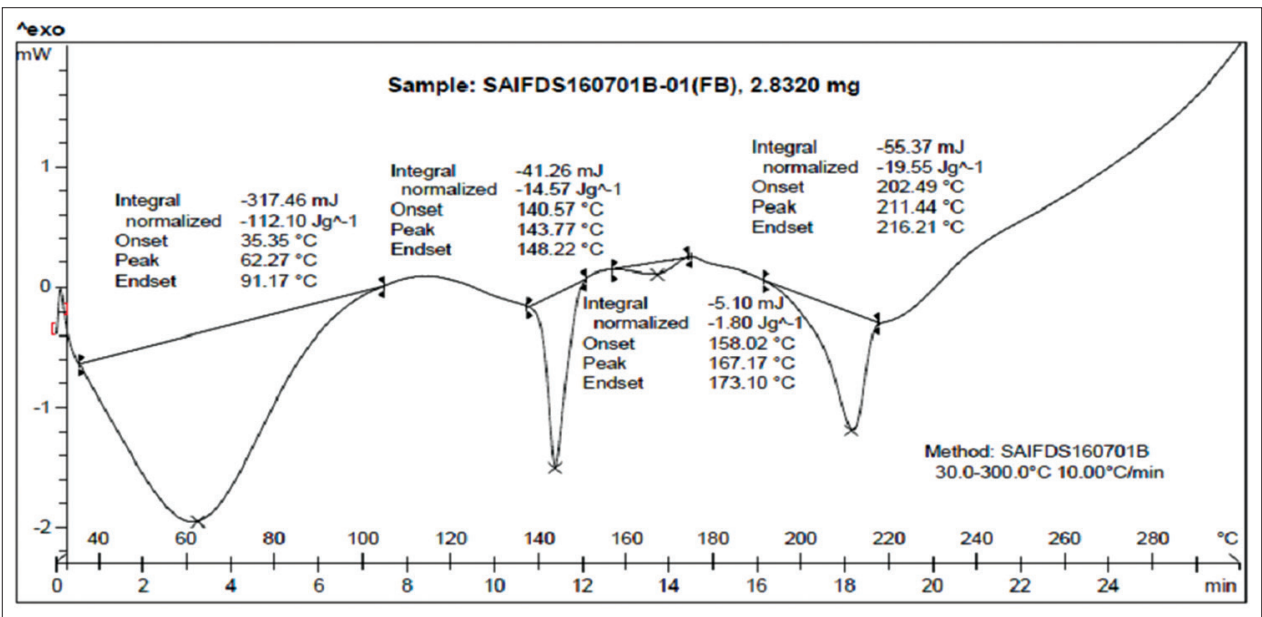

Fig. 4: Differential scanning calorimetry thermogram of optimized formulation

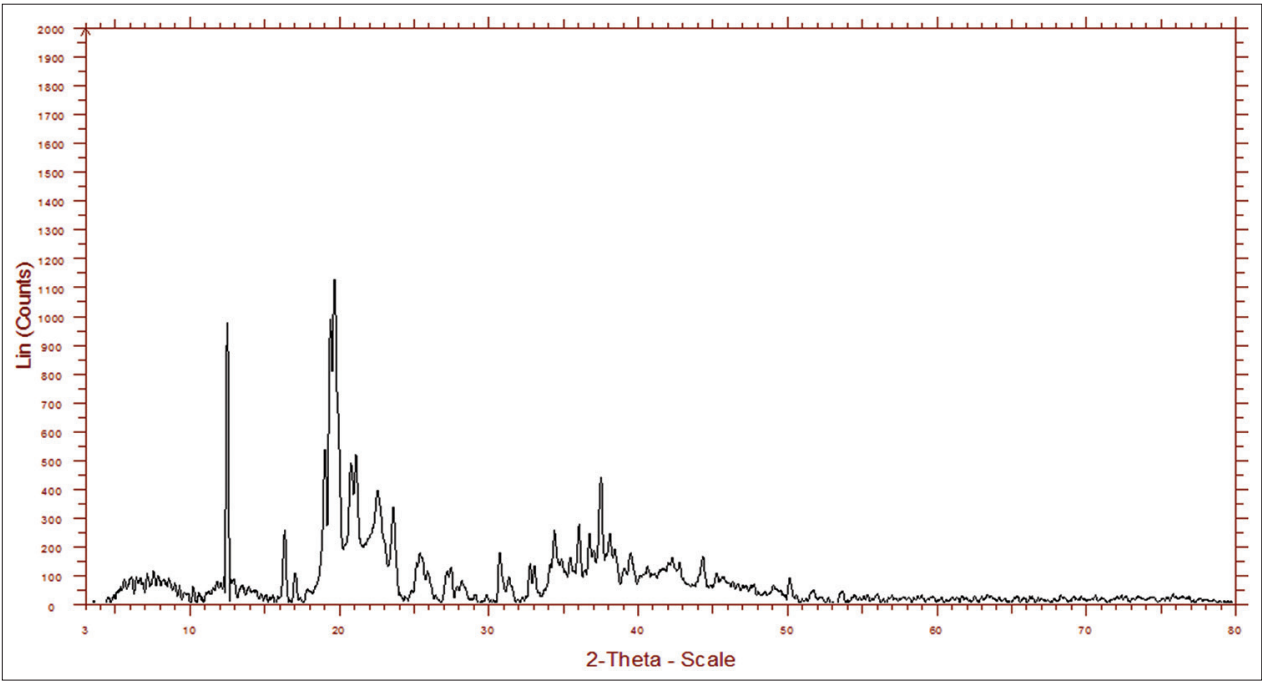

Fig. 5: Powered X-ray diffractometery of physical mixture

of 4.15 $\pm 0.11-4.52 \pm 0.17 \mathrm{~mm}$ which was all in acceptable USP ranges. The release of drug from ER tablets prepared at 5 different D: P ratios and the affects of different coexcipients on drug release rates can be seen from the Fig. 7. It was observed that about $90 \%$ drug was released in 12 hrs from the preparations prepared at D: P ratio 1:1.8 (4HC4), while the most extended drug release profiles were observed from the formulation prepared at D: P ratio 1:1.8 (4HC4).
Different kinetic models were applied to the optimized formulation and observed that the 4HC\$ followed zero order kinetic model. The best linearity was found in Higuchi model (where $n=1.11$ is the release exponent); applicability of data indicating non-Fickian diffusion.

The stability study for the selected formulation of 4HC4 was performed as per ICH guidelines. Stability studies were done for 3 months, and it 


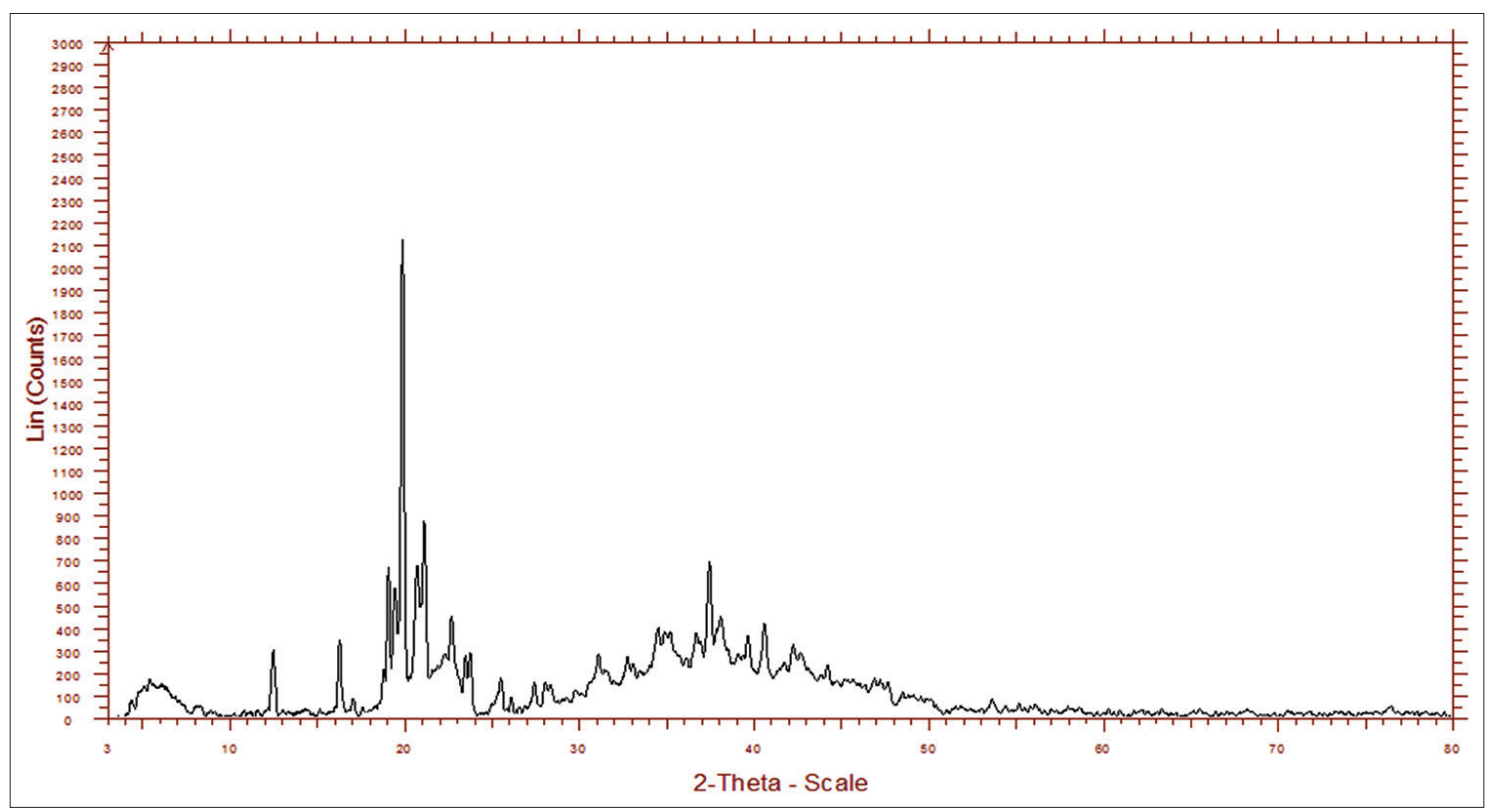

Fig. 6: Powered X-ray diffractometery of optimized formulation

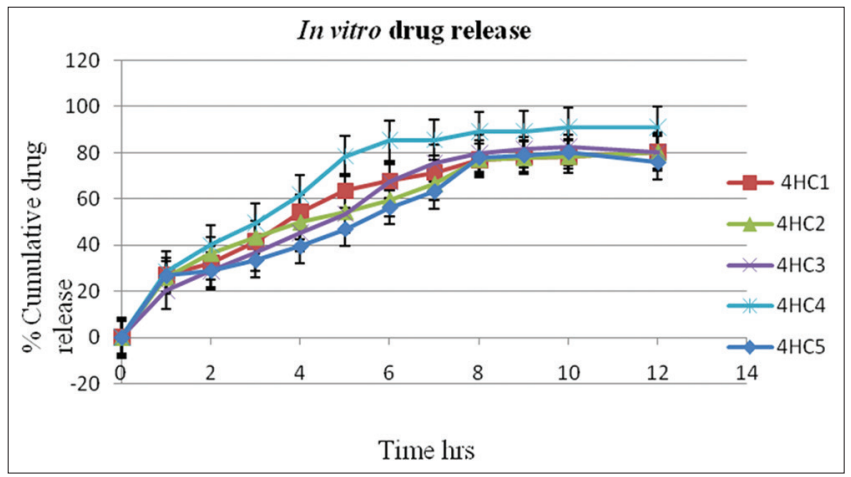

Fig. 7: In vitro dissolution data of extended release tablets

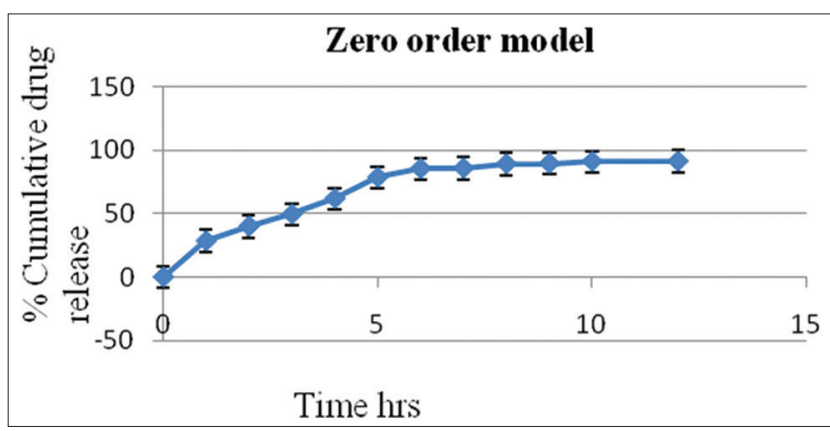

Fig. 8: Percentage cumulative drug release v/s time (zero order model) from the optimized formulation

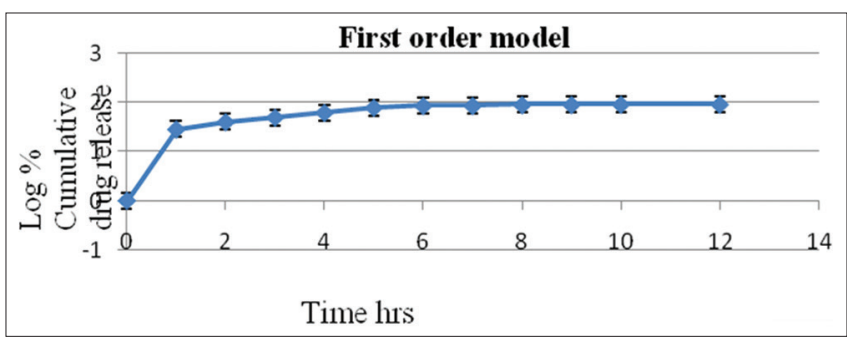

Fig. 9: Log cumulative drug release v/s time (first order model) from the optimized formulation

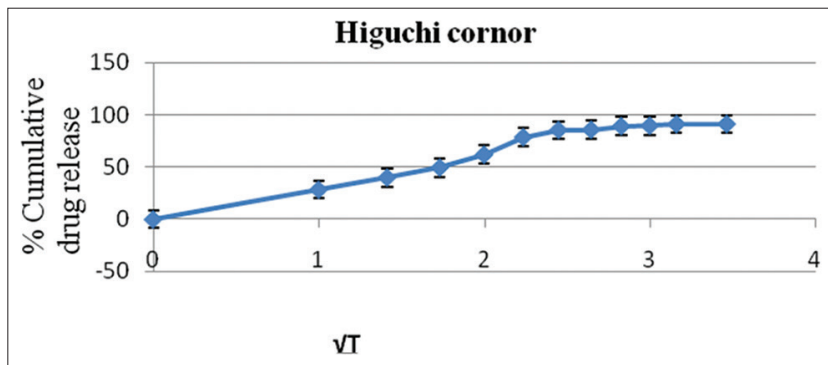

Fig. 10: Percentage cumulative drug release v/s square root time (Higuchi model) from the optimized formulation

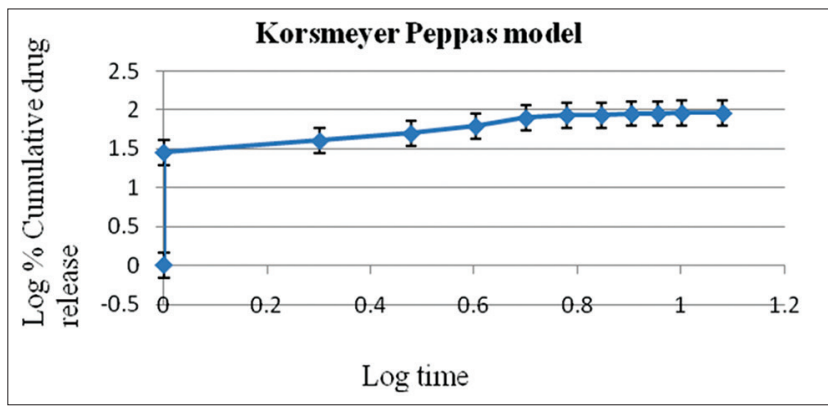

Fig. 11: Log cumulative drug release $\mathrm{v} / \mathrm{s}$ log time (Korsmeyer-Peppas model) from the optimized formulation

was noted that surface of tablet free from microbial or fungal growth or bad order. The tablets showed not $<98.5 \%$ drug content and all the physical parameters within the specified limit there was no significance in the values.

\section{CONCLUSION}

ER tablet containing chromene derivative was prepared successfully by direct compression method. All the tablets possessed good physical property. Among all the formulations, the formulation which prepared using HPMC K100 found to be effective in controlling the drug release up to $12 \mathrm{hrs}$. Stability studies revealed that there was no significant change in appearance, drug content and in vitro release of selected formulation (4HC4). It was observed that all batches gave the release by the diffusion-dissolution controlled mechanism. The dispersion of the 
Table 5: Release parameters of optimized formulation

\begin{tabular}{llllll}
\hline Code & Zero order & First order & Higuchi & Korsmeyer-peppas \\
\cline { 2 - 6 } & $\mathbf{R}^{2}$ & $\mathbf{R}^{2}$ & $\mathbf{R}^{2}$ & $\mathbf{n}$ & $\mathbf{R}^{2}$ \\
\hline $4 \mathrm{HC} 4$ & 0.809 & 0.456 & 0.946 & 1.113 & 0.576 \\
\hline
\end{tabular}

Table 6: Physical parameters of ER tablets (formula 4HC4 kept under stability study)

\begin{tabular}{|c|c|c|c|c|c|}
\hline Months & Hardness $\left(\mathrm{kg} / \mathrm{cm}^{2}\right)$ & Friability (\% loss) & Weight variation (mg) & Drug content (\%) & Physical appearance \\
\hline Initial & $3.1 \pm 0.341$ & $0.402 \pm 0.12$ & $167 \pm 0.40$ & $98.33 \pm 1.26$ & White \\
\hline After 2 week & $3.1 \pm 0.21$ & $0.48 \pm 0.17$ & $167 \pm 0.30$ & $98.57 \pm 0.30$ & White \\
\hline After 1 month & $3.2 \pm 0.35$ & $0.46 \pm 0.20$ & $166 \pm 0.22$ & $98.57 \pm 0.36$ & White \\
\hline After 2 months & $3.3 \pm 0.32$ & $0.46 \pm 0.18$ & $165 \pm 0.30$ & $98.54 \pm 0.30$ & White \\
\hline After 3 months & $3.4 \pm 0.31$ & $0.46 \pm 0.18$ & $167 \pm 0.40$ & $98.54 \pm 0.30$ & White \\
\hline
\end{tabular}

ER: Extended release

drug in the polymer network altered its dissolution profile at $\mathrm{pH} 7.2$, thus making it possible to obtain a gradual and prolonged release, and to modulate the release pattern.

Our preliminary findings on optimized ER tablets can be served for further investigation to assess the efficacy of the formulation by in vitro and in vivo IBD model.

\section{ACKNOWLEDGMENT}

Authors are thankful to Amrita Institute of Medical Sciences Kochi, Kerala, India, for giving support to complete the proposed work successfully.

\section{REFERENCES}

1. Khor B, Gardet A, Xavier RJ. Genetics and pathogenesis of inflammatory bowel disease. Nature 2011;474(7351):307-17.

2. Chandel S, Prakash A, Medhi B. Current scenario in inflammatory bowel disease: Drug development prospects. Pharmacol Rep 2015;67(2):224-9.

3. Lautenschläger C, Schmidt C, Fischer D, Stallmach A. Drug delivery strategies in the therapy of inflammatory bowel disease. Adv Drug Deliv Rev 2014;71:58-76.

4. Fahr A, Liu X. Drug delivery strategies for poorly water-soluble drugs. Expert Opin Drug Deliv 2007;4(4):403-16.

5. Kaur J, Aggarwal G, Singh G, Rana AC. Improvement of drug solubility using solid dispersion. Int J Pharm Pharm Sci 2012;4(2):47-53.

6. Uddin MR, Rashid MM, Alam MR. In vitro evaluation of oral extended release drug delivery system for trimetazidine dihydrochloride using methocel polymers. Int J Pharm Pharm Sci 2013;5(4):329-39.

7. Nanjwade BK, Mhase SR, Manvi FV. Formulation of extendedrelease metformin hydrochloride matrix tablets. Trop J Pharm Res 2011;10(4):375-83.

8. Thomas NA, Zachariah SM. Pharmacological activities of chromene derivatives: An overview. Asian J Pharm Clin Res 2013;6(2):11-5.

9. Keerthy HK, Mohan CD, Sivaraman Siveen K, Fuchs JE, Rangappa S, Sundaram MS, et al. Novel synthetic biscoumarins target tumor necrosis factor-a in hepatocellular carcinoma in vitro and in vivo. J Biol Chem 2014;289(46):31879-90.

10. Shah NK, Shah NM, Patel MP, Patel RG. Synthesis of 2-amino$4 \mathrm{H}$-chromene derivatives under microwave irradiation and their antimicrobial activity. J Chem Sci 2013;125(3):525-30.

11. Zachariah SM, Reshmi KP, Viswanad V, Nithya PS, Beegum FS, Rajan VK. In silico design, synthesis and in vitro studies of some novel 4-phenyl-4hchromene derivatives as antioxidant and anti-inflammatory agents. J Chem Pharm Res 2015;7(7):32-40.

12. Nitin K, Sushil K, Himanshu G, Sharma P. 3-hydroxy-2-(substituted phenyl)-4H-chromene-4-one derivatives-synthesis, spectral characterization and pharmacological screening. WRJB 2012;1(1):1-5.

13. Thumar NJ, Patel MP. Synthesis, characterization, and in vitro microbial evaluation of some new $4 \mathrm{H}$-chromene and quinoline derivatives of 1H-pyrazole. J Heterocycl Chem 2012;49(5):1169-78

14. Packiaraj JM, Venkateswaran CS, Janankiraman K. Formulation and evaluation of extended-release tablets of albuterol sulphate. Indo Am J Pharm Res 2013;3(12):1298-321.

15. Fiona P, Marina L, Ali RS. Investigation of a directly compressible metformin $\mathrm{HCl} 500 \mathrm{mg}$ extended release formulation based on hypromellose. J Young Pharm 2012;4(4):220-97. 